\title{
The research of human exposure to polybrominated diphenyl ethers and perfluoroocatane sulfonate
}

\author{
WANG YaWei \& JIANG GuiBin ${ }^{\dagger}$ \\ State Key Laboratory of Environmental Chemistry and Ecotoxicology, Research Center for Eco-Environmental Sciences, Chinese \\ Academy of Sciences, Beijing 100085, China \\ As two kinds of emerging chemicals, the pollution of polybrominated diphenyl ethers (PBDEs) and \\ perfluoroocatane sulfonate (PFOS) has been becoming a global environmental problem. Also, research \\ of the transport, transfer, bioaccumulation in organism, and toxicology of these two kinds of pollutant \\ is a hotspot in environmental sciences now. In this paper, we summarize and critically review the status \\ and progress of PBDEs and PFOS exposure to human beings. Further, data analyses based on statis- \\ tical methods are done to study the characters of PBDEs and PCBs concentrations in different regions \\ in the world.
}

polybrominated diphenyl ethers, perfluoroocatane sulfonate, human beings, breast milk, human blood, human tissue

Polybrominated diphenyl ethers (PBDEs) are widely used as brominated flame retardants (BFRs) in polyurethane foam, carpet, and electronic equipment such as computers and TV. In recent year, the global demand for PBDEs increases rapidly. In China, the production quantity of decabrominated diphenyl ether (deca-BDE) has ranked first among the largest BFRs since 1980s.

As a kind of additive BFRs, due to the lack of chemical bond binding, PBDEs can release to the ambient environment via the production, the use of these compounds, and the dismantling of the products to which these compounds are added, especially during electronic wastes (e-waste) recycling. PBDEs were initially determined in barracuda, eel, and sea trout in Sweden in $1981^{[1]}$. And then this group of pollutant was continuously found in sea fish, mussel, and sediments, etc, in the worldwide sites ${ }^{[2]}$. Jansson firstly suggested PBDEs should be attributed to a kind of global environmental pollutant in $1987^{[3]}$. The focus on PBDEs pollution initialized a detailed investigation about persistent organic pollutants (POPs) in Sweden's human breast milk. In this paper, other POPs in breast milk such as polychlorinated biphenyl (PCBs) decreased from 1970s to 1990s, but for PBDEs, the concentrations were increas- ing rapidly ${ }^{[4]}$. From then on, more and more studies reported PBDEs in air, soil, water, biosample, and human bodies. Recent works indicated that the concentrations of PBDEs in different environmental matrixes and human being are increasing rapidly ${ }^{[5-9]}$. Now, many countries including Europe, North America, Japan, and China have done related work to solve the environmental pollution of PBDEs.

Perfluoroocatane sulfonate (PFOS) is a representative of polyfluoroalkyl compounds (PFCs), which are used in industrial and commercial products. Due to their special chemical properties, more than one hundred products of PFCs have been synthesized, which are used as lubricants, adhesives, paper coatings, and fire-fighting foams, etc. ${ }^{[10-13]}$. The release of this kind substance to the ambient environment can occur via all kinds of pathway because of their usage. Recently, the publications about environmental behavior, toxicology, and current pollution of PFCs showed a rapid increasing trend and the risk assessment has been becoming a hotspot about

Received September 19, 2007; accepted December 21, 2007 doi: 10.1007/s11434-008-0122-y

†Corresponding author (email: gbjiang@rcees.ac.cn)

Supported by the Chinese Academy of Sciences (Grant No. KJCX2-YW-H04) and the National Natural Science Foundation of China (Grant Nos. 20737003 and 20707033) 
PFCs.

In this paper, we focus on and review the status and progress of PBDEs and PFOS exposure to human beings. Attention is paid to the discussion about several main congeners of PBDEs including BDE47, 99, 100, 153, and 154. Among the numerous PFCs derivatives, PFOS and perfluorooctanoic acid (PFOA) were the most notable ones.

\section{The toxicity of PBDEs and PFOS and intake pathway of human body}

\subsection{The toxicity of PBDEs and intake pathway of human body}

Previous studies have proved that the toxicity of PBDEs varies much due to the degrees of bromination. Evidence shows that penta-BDE in commercial products may be developmental neurotoxicants, neurochemical and hormonal deficits for the model animals such as rats and rabbit, while octa-BDE can cause malformation for fetus. The work on the toxicity of deca-BDE suggested that deca-BDE does not have acute toxicity. But there is evidence proving that it can debrominate to lower brominated congeners under the environmental condition and in living body, and then increase the harm to ambient environment and human beings. Chen et al. revealed that both pure PBDE congeners and commercial PBDE mixtures had Ah receptor binding affinities like $\operatorname{dioxin}^{[14]}$. Also, during the manufacturing PBDEs and combustion of production containing PBDEs, polybrominated dibenzo-p-dioxins and dibenzofurans $(\mathrm{PBDD} / \mathrm{Fs})$, which have the chemical structures of polychlorinated dibenzo-p-dioxins and dibenzofurans ( $\mathrm{PCDD} / \mathrm{Fs})$ can be produced and released into environment ${ }^{[15]}$.

There are several pathways for PBDE to be intaken into human body: (1) PBDEs can be biomagnified through food chains and then enter human body via dietary. Fishes especially those having higher lipid are the main sources of PBDEs ${ }^{[16]}$. (2) Breast milk is the main source of PBDEs for infant. Many reports have proved that high concentrations of BDE47, 99, and 153 can threaten children's health via maternal feeding ${ }^{[17,18]}$. (3) PBDEs in furniture, electrical equipment, and other materials can release indoor air ${ }^{[19]}$, and human body is passively exposed to PBDEs by imbibing the dust and particle in air.

\subsection{The toxicity of PFOS and intake pathway of human body}

Previous work revealed that experimental rats showed obvious decrease of body weight, poisoning of liver, muscle tremor, and even died with a high dose and by short period's exposure to PFOS ${ }^{[20,21]}$. The study of organ toxicity showed that PFOA and PFOS can disturb fatty acid combining with liver fatty acid-binding protein, influence the metabolizability of fatty acid, and decrease the activity of all kinds of enzymes in liver cell $^{[22]}$. There is also other evidence proving that PFOS and PFOA can induce neurotoxicity ${ }^{[23]}$, hurt cardiac muscle ${ }^{[24]}$, influence the growth of embryo, and have procreation and inherited toxicity ${ }^{[25,26]}$.

The main intake paths of PFOS and PFOA for human body, which are similar to those of PBDEs, are via food intake, breath, and the biodegradation of other PFCs ${ }^{[10]}$.

\section{The concentrations of PBDEs and PFOS in human bloods}

\subsection{The concentrations of PBDEs in human bloods}

It is proved by experimental rats that BDE47 can enter living body through skin, which is perhaps also a pathway for PBDE to enter human bodies ${ }^{[27,28]}$. Many researches have been focused on PBDEs in human tissues, blood, and breast milk. Figure 1 shows the concentrations of main congeners BDE47, 99, 100, 153, and 154 in human blood in the world ${ }^{[29-44]}$. The database includes the concentrations of PBDEs in 1157 blood samples from 10 countries between 1977 and 2007. From the box chart we can find that the highest concentration of congener is BDE47, accounting for $47.9 \%$ of the total PBDEs. The next congener is BDE153, accounting for $17.3 \%$ of the total of PBDEs.

The concentrations of PBDE vary greatly from country to country (in a range of $0.44 \mathrm{ng} / \mathrm{g}$ and $71 \mathrm{ng} / \mathrm{g}$ (lipid)) and the highest occurs in the United States. Other studies also pointed out that the inhabitants in USA live in a relatively high exposure environment of PBDEs ${ }^{[45]}$. In China, the PBDEs concentrations in human bloods are lower than those in Europe and North America.

Generally, PBDEs concentrations in human body have increased by 100 -fold in the past 30 years. The investigation of human blood in Norway showed that the concentrations of PBDEs increased from $0.44 \mathrm{ng} / \mathrm{g}$ in 1977 to $3.1 \mathrm{ng} / \mathrm{g}$ in 1999. Correspondingly, the concentrations in Germany increased from $2.66 \mathrm{ng} / \mathrm{g}$ in 1986 to $4.53 \mathrm{ng} / \mathrm{g}$ in 1999. And the study in USA also showed a rapid increasing trend. PBDEs concentrations in American human body have increased by more than 10 -fold in 


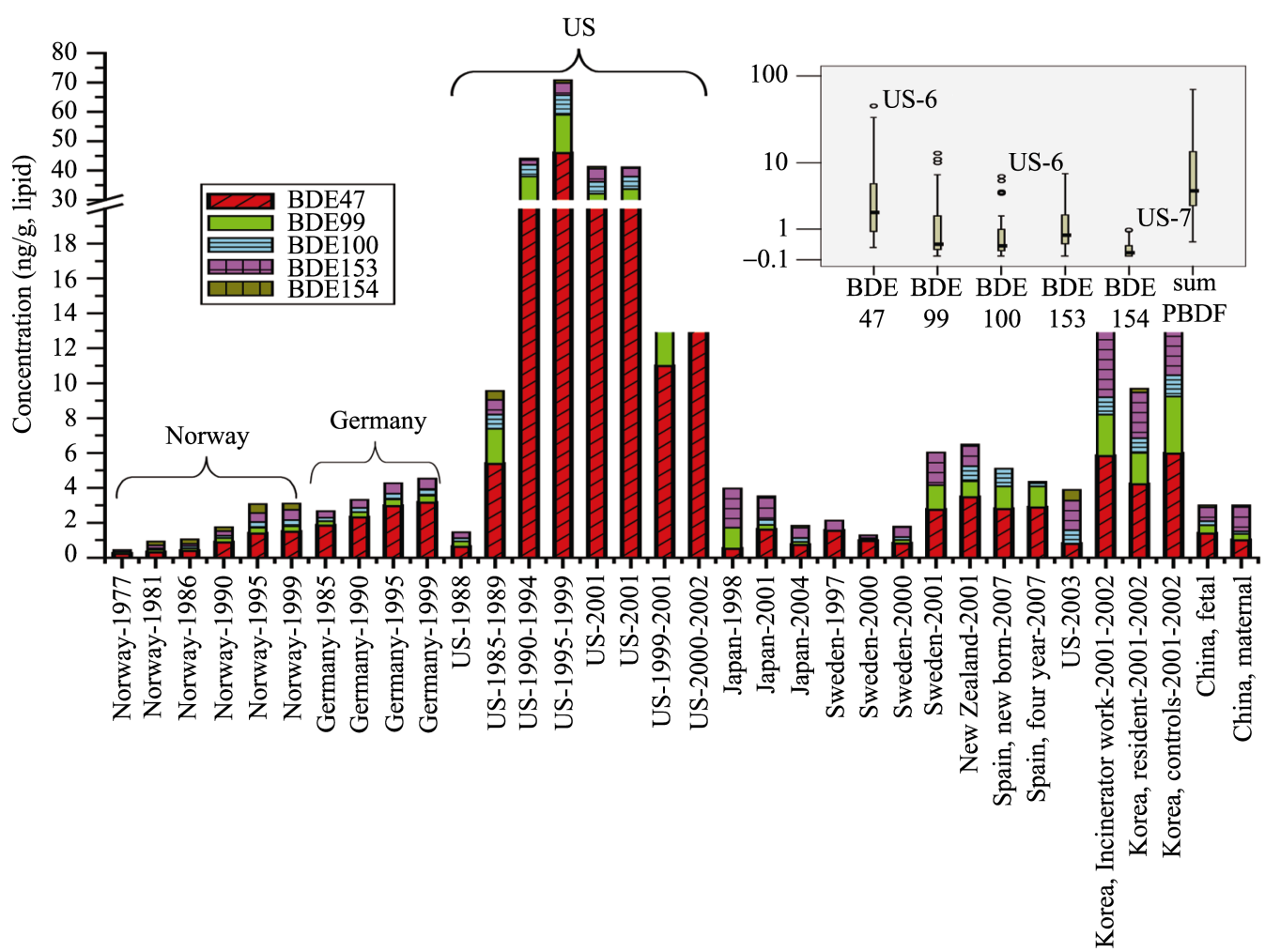

Figure 1 The distribution of PBDEs concentrations in human blood from different countries. The insert figure is the box chart of concentrations of PBDEs.

recent years and those in Japanese human body are about 5 -fold.

Principal component analysis (PCA) can project multidimensional data onto two-dimensional schematic, which is a better way to make comparison of the congener distributions. In order to further compare and analyze the characters of the concentrations in different regions, PCA was executed with SPSS 13.0 for Windows Release 13.0 (SPSS Inc., 1989-2006) and the full data sets of five main concentrations (BDE47, 99, 100, 153, and 154) were used in PCA. The first two principal components explained $94 \%$ of the variability of the data set. Principal component 1 versus principal component 2 is shown in Figure 2(a), which suggests that the PBDEs concentrations in USA's human blood were significantly higher than those in other countries. Sjödin also revealed that from 1985 to 1992, BDE47, 99, 100, 153 and the sum of PBDEs showed a linear increasing trend ${ }^{[41]}$. Because the concentrations of human blood samples in USA are so high, the information in other countries can be concealed when executed PCA. So the database, which excluded the information of USA, was re-analyzed using PCA analysis. The result (Figure 2(b)) showed that in Asia, the concentrations of PBDEs in human blood collected from South Korea were higher than those in China and Japan. In this work ${ }^{[43]}$, the researchers specially focused on PBDEs occupational exposure in incinerator workers and selected a group of the general population residing far from the sampling sites as the control samples. The investigation indicated that no obvious evidences proved that the concentrations in incinerator workers' bloods were higher than those in controlled human bodies. They considered that solid waste incinerators did not obviously influence the PBDEs concentrations in human body. But the incineration can produce other toxic compounds including $\mathrm{PBDD} / \mathrm{Fs}$ and also increase the toxicity of the incinerator environments and the health risks or incinerator workers. Figure 2(b) also shows that in the United Kingdom, BDE-154 in blood is higher than that in other countries.

\subsection{The concentrations of PFOS and PFOA in hu- man blood}

PFOS and PFOA are two main PFCs in environment and human body. The first study about PFCs in human blood was done in $1960 \mathrm{~s}^{[46]}$. Recently, based on the studies of PFOS and PFOA on the workers employed by PFCs production factories, the research work relating to 


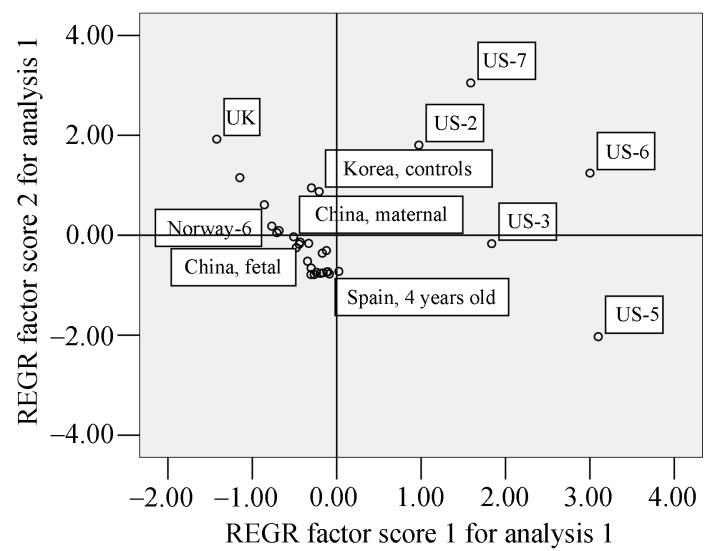

(a)

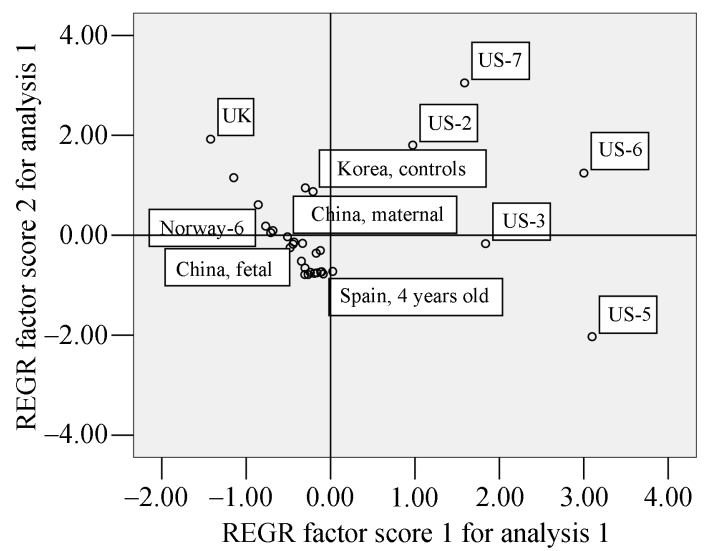

(b)

Figure 2 PCA results of the concentrations in human bloods from different countries. (a) For principal component 1, the loading values of BDE47, 99, 100,153 , and 154 are $0.918,0.909,0.880,0.545$, and 0.328 , respectively; for principal component 2 , the corresponding values are $0.378,0.392,0.459$, $0.731,0.908$, respectively; (b) the PCA results except the data of USA. For principal component 1, the loading values of BDE47, 99, 100, 153, 154, and the sum of PBDEs are $0.943,0.945,0.900,0.802,0.072$; for principal component 2 , the corresponding values are $-0.063,-0.001,0.381,0.213,0.987$.

PFOS and PFOA in human blood was carried out worldwide. The finished work included the studies about the concentration in human blood in USA, Colombia, Brazil, Italy, Poland, Belgium, India, Malaysia, South Korea, Japan, and China ${ }^{[47-49]}$. Table 1 lists the concentrations of PFOS and PFOA in human bloods from different countries between 1974 and 2005. And the levels ranged from under limit of detection (LOD) to up to more than one thousand $\mathrm{ng} / \mathrm{mL}$.

Figure 3 exhibits PFOS and PFOA in whole blood and serum worldwide and the temporal trends in USA and Japan. The concentration of PFOS in most samples is higher than that of PFOA. Generally, the concentrations in Europe and North America are the highest in the world. In USA, the levels did not obviously change in $1974-2000$, but in the period of $2000-2005$, the concentration showed a rapid increase. In Japan, no obvious change of PFOS and PFOA concentrations was found between 2001 and 2004 although the pollution levels varied greatly from county to county.

The highest value occurred in USA ${ }^{[52]}$. Ehresman et al. collected blood samples from participants employed by 3M Company including fluorochemical production workers, laboratory researchers, and administrative employees and found that the average concentrations of PFOS and PFOA in serum were 134 and $1046 \mathrm{ng} / \mathrm{mL}$, respectively, and the highest was up to 880 and 7320 $\mathrm{ng} / \mathrm{mL}$, respectively. The average concentration in the whole blood was 68 and $535 \mathrm{ng} / \mathrm{mL}$, respectively. They also found that the concentrations in laboratory re- searchers were higher than those in production workers and administrative employees. The concentrations ratio of serum to plasma was about $1: 1$, which was independent of the level of concentrations measured.

The study about the concentrations in serum of South Korea showed that the concentration of PFOA was higher than that of PFOS, indicating that specific source existed in some districts in this country ${ }^{[48]}$.

\section{The concentrations of PBDEs and PFOS in human breast milk}

PBDEs can enter infant body via breast milk. Current researches found that the concentration level of PBDEs in human breast milk reached the concentration levels in other tissues ${ }^{[67]}$. The concern about BFRs pollution in environment was just aroused from a detailed report about the PBDEs in Sweden's breast milk ${ }^{[9,68]}$. In this report, other POPs showed a decreasing trend from 1970 s to 1990 s, but for PBDEs, the concentrations appeared a continuous increase. The concerned review pointed out that the concentrations of PBDEs in human breast milk have a 10-fold higher than those in 1970s and BDE47 is the main congener ${ }^{[69]}$.

Figure 4 is the box chart of the concentrations of PBDEs (BDE47, 99, 100, 153, and 154) in milk from 22 countries ${ }^{[28,70-95]}$. Similar to the distribution of PBDEs in blood, the concentrations in milk varied greatly from country to country and from period to period. The concentrations of the total of PBDEs ranged from 0.07 to $384.6 \mathrm{ng} / \mathrm{g}$ (lipid). BDE47 and 153 account for $51.1 \%$ 
(a)

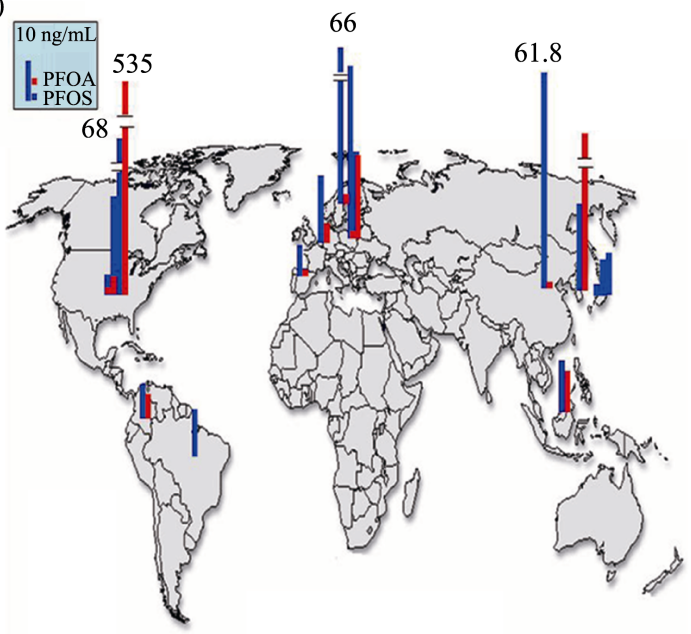

(b)

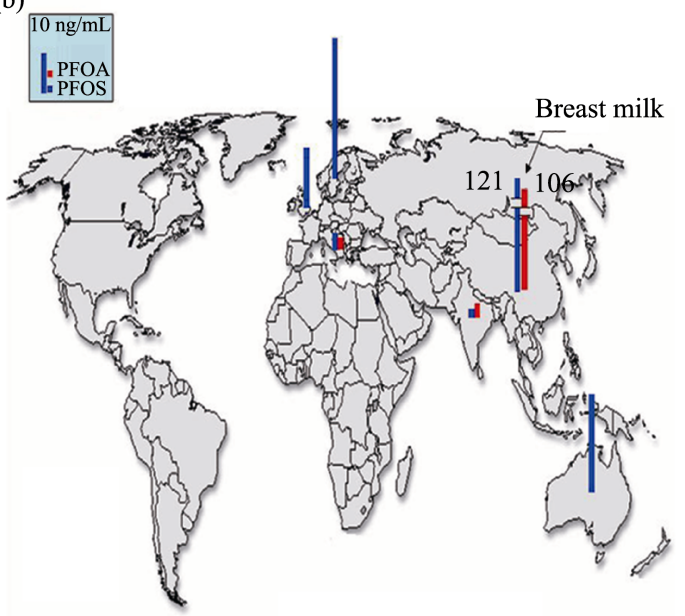

(c)
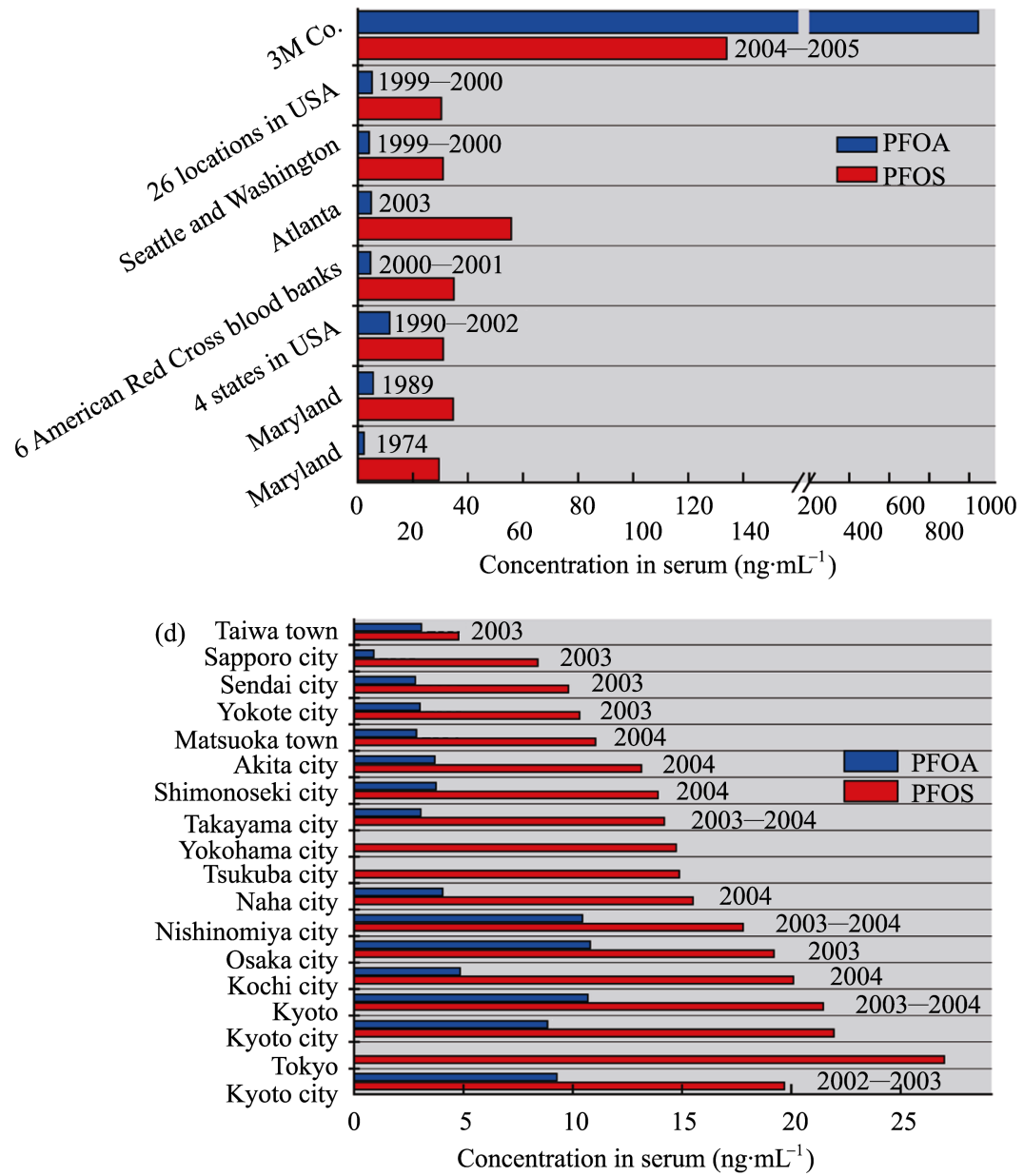

Figure 3 The concentrations of PFOA and PFOS in blood in different countries. (a) PFOA and PFOS in whole blood; (b) PFOA and PFOS in serum with a temporal trend. 
Table 1 The concentrations of PFOA and PFOS in different countries (ng/mL)

\begin{tabular}{|c|c|c|c|c|c|c|c|}
\hline Country & Sampling time & No. & PFOS & No. & PFOA & Matrix & Ref \\
\hline Japan & 2003 & 10 & 10.3 & & & whole blood & [50] \\
\hline Japan & 2003 & 15 & 8.9 & 15 & nd & whole blood & [51] \\
\hline Japan & 2003 & 15 & 2.9 & 15 & nd & whole blood & [51] \\
\hline America & $2004-2005$ & 17 & 68 & 12 & 535 & whole blood & [52] \\
\hline America & $2004-2005$ & 299 & 4.9 & 299 & 1.6 & whole blood & [53] \\
\hline America & $2001-2002$ & 57 & 24.2 & 57 & 4.26 & whole blood & [54] \\
\hline Poland & 2003 & & 21 & & 3.3 & whole blood & [55] \\
\hline Poland & 2003 & 25 & 42.14 & 25 & 20.5 & whole blood & [48] \\
\hline Spain & 2006 & 48 & 7.64 & 48 & 1.8 & whole blood & [56] \\
\hline Sweden & $1997-2000$ & 66 & 66 & 66 & 2.4 & whole blood & [57] \\
\hline China & 2004 & 85 & 52.7 & 85 & 1.59 & whole blood & [58] \\
\hline Colombia & 2003 & 56 & 8.28 & 56 & 6.16 & whole blood & [48] \\
\hline Brazil & 2003 & 27 & 11.74 & 27 & $<20$ & whole blood & [48] \\
\hline Belgium & $1998-2000$ & 20 & 16.3 & 20 & 4.82 & plasma & [48] \\
\hline Malaysia & 2004 & 23 & 12.74 & 23 & 10 & whole blood & [48] \\
\hline Korea & 2003 & 50 & 21.2 & 50 & 61.8 & whole blood & [48] \\
\hline America & 1974 & 178 & 29.5 & 127 & 2.3 & serum & [59] \\
\hline America & 1989 & 178 & 34.7 & 177 & 5.6 & serum & [59] \\
\hline America & $1990-2002$ & 23 & 31.1 & 23 & 11.6 & serum & [60] \\
\hline America & $2000-2001$ & 645 & 34.9 & 645 & 4.6 & serum & [61] \\
\hline America & 2003 & 20 & 55.8 & 22 & 4.89 & serum & [62] \\
\hline America & $1999-2000$ & 238 & 31 & 238 & 4.2 & serum & [63] \\
\hline America & $1999-2000$ & 1562 & 30.4 & 1562 & 5.2 & serum & [64] \\
\hline America & $2004-2005$ & 18 & 134 & 12 & 1046 & serum & [65] \\
\hline Italy & 2001 & 50 & 4.32 & 50 & $<3$ & serum & [48] \\
\hline India & 2000 & 45 & 1.85 & 45 & 3.38 & serum & [48] \\
\hline Japan & 2002 & 38 & 16.15 & 38 & 8.68 & serum & [48] \\
\hline Japan & 2003 & 3 & 27 & - & - & serum & [48] \\
\hline Sweden & & 17 & 33.4 & - & - & plasma & [65] \\
\hline Australia & & 40 & 23.4 & - & - & serum & [65] \\
\hline UK & & 13 & 14.2 & - & - & plasma & [65] \\
\hline Japan & & 22 & 21.47 & 22 & 10.7 & serum & [66] \\
\hline
\end{tabular}

No, The number of samples.

and $18.1 \%$ of the total of PBDEs, respectively.

Figure 4 indicates that higher concentrations of PBDEs in milk occurred in North America. Thereinto, the study about PBDEs in breast milk from the northeast Pacific revealed that for some samples, BDE153 concentrations were higher than those of BDE4 $7^{[84]}$. In Asia, the concentrations showed obviously low levels compared with other regions. The concentration levels in milk from South Korea are similar to those from China and Japan, which is different from the results of blood. Further, PCA was used to analyze the character of the dataset and the score plot is shown in Figure 5(a). In order to avoid the disturbance of the data about USA, after deleting them, we re-analyzed the data (Figure 5 (b)).

From Figure 5(a), we can see that the concentrations of PBDEs in breast milk from USA are significantly higher than those in other countries. The next high level appears in Canada. For Europe (Figure 5(b)), except
United Kingdom, the other countries belong to the group of Asian countries, which are at the low level of PBDEs in milk in the worldwide.

The works on PFOS and PFOA in breast milk is relatively scarce. So et al. collected human breast milks from Zhoushan, China to evaluate the health risks in infants associated with exposure to PFCs ${ }^{[96]}$. PFOS and PFOA were detected in all samples and the concentrations ranged from $40-360$ to $47-210 \mathrm{ng} / \mathrm{L}$, respectively. The concentrations were not correlated with maternal age, weight and infant's weight. But significant relationships were found between rate of consumption of fishes and other PFCs concentrations.

Kärrman et al. analyzed the PFCs in Swedish breast milk collected from 1996 to 2004 and found that five PFCs compounds could be detected ${ }^{[97]}$. Thereinto, PFOS was detected in all samples. The average value was $1 \%$ of the corresponding concentrations in bloods 


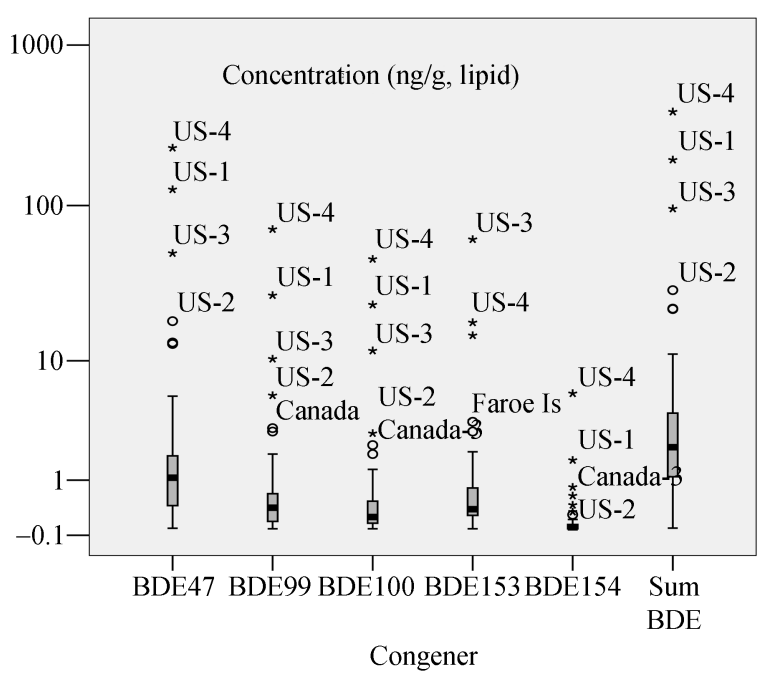

Figure 4 The box chart of PBDEs in breast milk from different countries.

and there is a linear relationship between these two groups of data. The number of samples that were detected PFOA was relatively small. PFOS and PFOA levels in composite milk samples unchanged between 1996 and 2004 with a total variation of $20 \%$ to $32 \%$ coefficients.

\section{The concentrations of PBDEs in hu- man tissues}

Table 2 lists PBDEs in adipose tissue collected from Asia, Europe, and North America. Different countries showed different concentrations of PBDEs. The most important congeners BDE47 and 153 accounted for 43\%

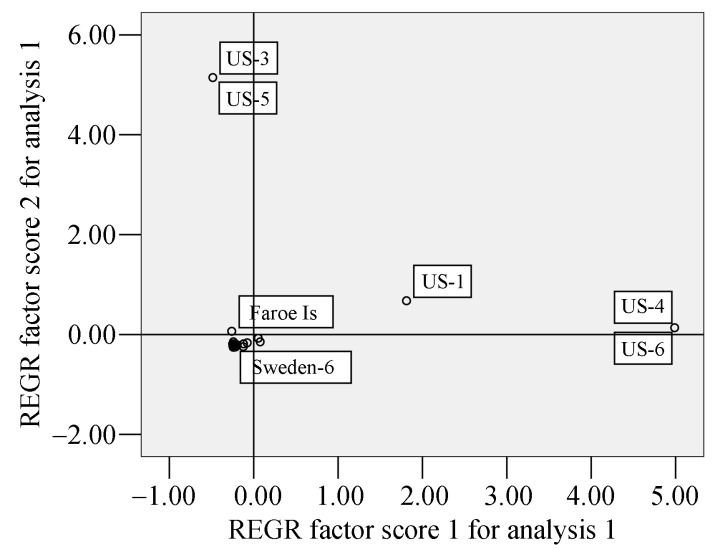

(a) and $26.3 \%$ of the total of PBDEs, respectively.

The research of PBDE in human tissue is mainly focused in Japan and Singapore. From 1970s to 2004 (Table 2), the concentrations of PBDEs in adipose tissue in Japan increased from $0.023 \mathrm{ng} / \mathrm{g}$ to $8.39 \mathrm{ng} / \mathrm{g}$ with an exponent trend. The concentrations of PBDEs in tissue from Singapore were similar to those from Japan. But the main congener was BDE47 and BDE99, 100, 153, and 154 were lower than $\operatorname{LOD}^{[100]}$.

The levels of PBDEs in adipose tissue from European samples are comparable to those from Asia. But the ratio of BDE99 is higher and no obvious change was found with the temporal trend. The highest concentration in human tissue exists in USA. An investigation in 20032004 showed that the concentrations of PBDEs in this country were 2 orders of magnitude higher than those in Europe and Asia. The average value is $399 \mathrm{ng} / \mathrm{g}$, which is 10 -fold higher than that in 1990s, and the highest is even up to $9639 \mathrm{ng} / \mathrm{g}$. This suggested that individual concentrations are highly correlated with the occupational and exposure environment.

\section{The relationship between the concen- trations of PBDEs and PFOS and expo- sure environment}

The concentrations of PBDEs and PFCs in human body are obviously related to the ambient environment. Many studies reported that the pollutant contents in bloods and human milk from exposure inhabitants were significantly higher than those of controlled people. Qu

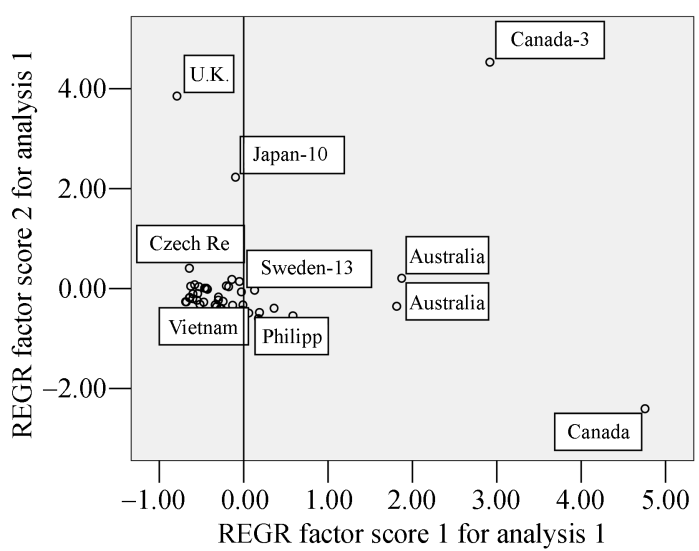

(b)

Figure 5 PCA results of the concentrations in breast milk from different countries. (a) For component 1, the loading values of BDE47, 99, 100, 153, and 154 are $0.964,0.983,0.957,0.217,0.979$, respectively; for component 2 , the corresponding values are $0.253,0.183,0.285,0.975$, and 0.171 ; (b) the result excluding the data of USA. For component 1 , the loading values are: $0.910,0.938,0.907,0.701$, and 0.327 ; for component 2 , the corresponding values are $0.283,0.286,0.372,0.384$, and 0.937 . 
Table 2 PBDEs concentrations in adipose tissue from different countries (ng/g, lipid).

\begin{tabular}{|c|c|c|c|c|c|c|c|c|c|c|}
\hline Country & Type & Date & No. & 47 & 99 & 100 & 153 & 154 & PBDE & Ref. \\
\hline Japan & adipose & 1970 & 10 & 0.017 & 0.004 & 0.002 & & & 0.023 & [98] \\
\hline Japan & adipose & 2000 & 10 & 0.46 & 0.12 & 0.25 & 0.38 & 0.06 & 1.27 & [98] \\
\hline Japan & liver & 2001 & 10 & 1.38 & 0.18 & 0.22 & 1.55 & 0.14 & 3.48 & [34] \\
\hline Japan & adipose & $2003-2004$ & 28 & 1.31 & 0.20 & 0.56 & 2.45 & 0.16 & 8.39 & [99] \\
\hline Singapore & adipose & $2003-2004$ & 16 & 2.89 & n.d. & n.d. & n.d. & n.d. & 3.63 & [100] \\
\hline Belgium & adipose & 2000 & 20 & 1.45 & 0.28 & 0.48 & 2.49 & & 4.70 & [101] \\
\hline Sweden & adipose & 1994 & 5 & 2.37 & 1.29 & 0.29 & 0.96 & 0.06 & 4.97 & [102] \\
\hline Sweden & adipose & 1994 & 1 & 8.80 & 1.10 & 1.80 & 1.70 & & 13.4 & [103] \\
\hline Finland & placenta & 1996 & 11 & 0.77 & 0.41 & & 0.40 & & 1.58 & [73] \\
\hline Finland & adipose & 1998 & 10 & 6.14 & 2.02 & & 2.18 & & 10.3 & [104] \\
\hline Finland & adipose & & 37 & 0.55 & 0.74 & n.a. & 0.30 & n.a. & 1.59 & [105] \\
\hline Spain & adipose & 1998 & 13 & 1.36 & 0.42 & 0.51 & 1.83 & & 4.12 & {$[106]$} \\
\hline Czech Republic & adipose & 2000 & 14 & 0.40 & 0.12 & 0.13 & 0.41 & 0.03 & 1.09 & [108] \\
\hline Czech Republic & adipose & 2000 & 10 & 1.18 & 0.34 & 0.59 & 0.52 & 0.06 & 2.69 & [108] \\
\hline US & breast adipose & $1996-1998$ & 52 & 18.0 & 6.60 & 3.20 & 4.10 & 6.40 & 38.3 & [109] \\
\hline US & breast adipose & 1997 & 22 & 18.3 & 6.59 & 3.17 & 4.09 & 6.40 & 38.6 & [109] \\
\hline US & adipose & $2003-2004$ & 52 & 132 & 74.4 & 67.7 & 91.8 & 8.30 & 399 & [110] \\
\hline
\end{tabular}

et al. investigated the exposure to PBDEs among workers at an electronic waste dismantling region in Guangdong, China ${ }^{[111]}$. The data showed that the concentrations of PBDEs in blood from occupational exposure workers were 10-20 times higher than those in the controlled group. BDE209 was the dominant congener and the highest was observed to be about $3436 \mathrm{ng} / \mathrm{g}$ (lipid), which was the highest concentration in human worldwide. Similarly, Thuresson et al. investigated the exposure to commercial deca-BDE in workers manufacturing or handling flame-retarded rubber ${ }^{[112]}$. High concentrations of BDE209, nona-BDEs, and octa-BDEs were detected and relatively low concentrations of lower brominated congeners such as BDE47 and 100 were also found. The investigation also proved that the debromination of BDE209 exists in human body. Thuresson et al. followed up the concentrations change of PBDEs in e-waste dismantling worker before (1997) and after (2000) the improvement of working conditions ${ }^{[113]}$. The study clearly showed that the industrial hygiene improvement could reduce the occupational exposure to higher brominated congeners. Although the amount of goods doubled in 2000 compared with 1997, a significant decrease in the serum levels of BDE183 and 209 was found. But the levels of BDE47 and BDE153 did not significantly change, which were thought to be longer half-lives (1.8 years and 6.5 years, respectively).

The pathway for the PBDEs in human body is a hotspot in current research. Wu studied the relationships between the concentrations of PBDEs in human milk from Massachusetts, USA and data about personal characteristics, diet, home furniture, and electrical device, etc. ${ }^{[17]}$. PBDEs concentrations were closely related to the concentrations in house dust, dietary habits, particularly the consumption of dairy products and meats, but not correlated with the consumption of fishes. Also, the PBDE levels in milk were positively correlated with the concentrations of PBDEs in house dust, which showed that indoor environment and diet both play important roles in human exposure to PBDEs even though the clear intake pathway into human body was not confirmed. There are also other evidence proving PBDE levels in pure vegetarians, which showed a decrease trend with the increase of ages ${ }^{[114]}$. Meng et al. further compared the pathway of PBDEs into human body and revealed that the amounts of PBDEs by inhalation for infants were far higher than those for adult. In China, PBDEs in fishes for food and the consumptions of fishes were at a relatively low level in the world, while the amounts by inhalations were higher than those in other countries $^{[115]}$.

For PFCs, food intake seems a prominent pathway into human body. Falandysz et al. proved that besides PFOS and PFOA, there were 8 PFCs compounds to be found to accumulate in human body by studying PFCs in human bloods from Baltic coast. Also, individuals who had a high fish intake contained the highest load of PFCs compared with other human subpopulations ${ }^{[55]}$. 


\section{Conclusions}

As two kinds of emerging pollutants, PBDEs and PFCs have extensively spread in global environment and threatened the ecosystem. In the past, researchers spent lots of energy to study the environmental behaviors, transformation, transfer, toxicity etc. of these compounds. Many countries have made related policies and laws to restrict or prohibit the production and use of these two groups of compounds. For example, the uncertainties arising from the risk assessment and high level of uncertainty associated with potential risks make the European Union (EU) ban the use of penta-BDE and octa-BDE. US-EPA also has established strict regulation to restrict the production and usage of PFCs. The environment risk assessment required further work about the

1 Andersson Ö, Blomkvist G. Polybrominated aromatic pollutants found in fish in Sweden. Chemosphere, 1981, 10: 1051-1060

2 Watanabe I, Kashimoto T, Tatsukawa R. Polybrominated biphenyl ethers in marine fish, shellfish and river and marine sediments in Japan. Chemosphere, 1987, 16: 2389-2396

3 Jansson, B, Asplund, L, Olsson, M. Brominated flame rerardantsubiquitous environmental pollutants? Chemosphere, 1987, 16: 2343-2349

4 Li A, Rockne K J, Sturchio N, et al. Polybrominated diphenyl ethers in the sediments of the Great lakes 4 Influencing factors, trends, and implications. Environ Sci Technol, 2006, 40: 7528-7534

5 Rayne S, Ikonomou M G, Antcliffe B. Rapidly increasing polybrominated diphenyl ether concentrations in the Columbia River System from 1992 to 2000. Environ Sci Technol, 2003, 37: 2847-2854

6 Song W, Ford J C, Li A, et al. Polybrominated diphenyl ethers in the sediments of the Great Lakes 3 Lakes Ontario and Erie. Environ Sci Technol, 2005, 39: 5600-5605

7 Kim B H, Ikonomou M G, Lee S J, et al. Concentrations of polybrominated diphenyl ethers, polychlorinated dibenzo-p-dioxins and dibenzofurans, and polychlorinated biphenyls in human blood samples from Korea. Sci Total Environ, 2005, 336: 45-56

8 Thomsen C, Lundanes E, Becher G. Brominated flame retardants in archived serum samples from Norway: A study on temporal trends and the role of age. Environ Sci Technol, 2002, 36: 1414-1418

9 Sudaryanto A, Kajiwara N, Takahashi S, et al. Geographical distribution and accumulation features of PBDEs in human breast milk from Indonesia. Environ Pollut, 2007, 151: 130-138

10 Guo R, Cai Y Q, Jiang G B, et al. Current research of perfluorooctane sulfonate. Prog Chem, 2006, 18: 808-813

11 Houde M, Martin J W, Letcher R J, et al. Biological monitoring of polyfluoroalkyl substances: A review. Environ Sci Technol, 2006, 40: $3463-3473$

12 Prevedouros K, Cousins I T, Buck R C, et al. Sources, fate and transport of perfluorocarboxylates. Environ Sci Technol, 2006, 40: $32-44$ environmental behavior, transformation, and bioaccumulations/biomagnifications via food chain for PBDEs and PFCs. In China, the research about these two groups of compounds just begins. But in the last several years, the study level has advanced rapidly. Many laboratories including sanitation system have focused on emerging chemicals, especially for the risk assessment in special areas, for example, e-waste dismantling area. But up to now, people are not clear about the source, the transformation and transport, the environmental repair, and the potential risk assessment about these two groups of emerging chemicals. The work will estimate the release of the emerging chemicals to ambient environment and the consumption of these contaminants. And it will assess ecology damage and apply evidence to carry out regulation and laws for the government.

13 Jin Y H, Tang X W, Cao X J, et al. Global environmental pollution and biological effects of perfluorooctane sulfonate. Chin J Nature 2002, 24: $344-348$

14 Chen G, Konstantinov A D, Chittim B G, et al. Synthesis of polybrominated diphenyl ethers and their capacity to induce CYP1A by the Ah receptor mediated pathway. Environ Sci Technol, 2001, 35: $3749-3756$

15 Thoma H, Hauschulz G, Knorr E, et al. Polybrominated dibenzofurans (PBDF) and dibenzodioxins (PBDD) from the pyrolysis of neat brominated diphenylethers, biphenyls and plastic mixtures of these compounds. Chemosphere, 1987, 16: 277-285

16 Lind Y, Aune M, Atuna S, et al. Food intake of the brominated flame retardants PBDEs and HBCD in Sweden. Organohalog Compd, 2002, 58: $181-184$

17 Wu N, Herrmann T, Paepke O, et al. Human exposure to PBDEs: Associations of PBDE burdens with food consumption and house concentrations. Environ Sci Technol, 2007, 41: 1584-1589

18 Betts K S. A new record for PBDEs in people. Environ Sci Technol 2005, 39: 296A

19 Knoth W, Mann W, Meyer R, et al. Polybrominated diphenylether in house dust. Organohalog Compd, 2002, 58: 213-216

20 Olson C T, Andersen M E. The acute toxicity of perfluomoctanoic and perfluoroectanoic acid in male rats and effects on tissue fatty acid Toxicol Appl Pharmacol, 1983, 70: 362-372

21 Haughom B, Spydevold O. The mechanism underlying the hypolipemic effect of perfluorooctanoic acid (PFOA), perfluorooctane sulphonic acid (PFOSA) and clofibric acid. Biochim Biophys Acta, 1992, 1128: $65-72$

22 Luebker D J, Hansen K J, Bass N M, et al. Interactions of fluorochemicals with rat liver fatty acid-binding protein. Toxicology, 2002, 176: $175-185$

23 Li Y, Jin Y H. Effects of perfluorooctanesulfonylsulfonate on glutamate concentration of central nervous system in rats. J Health Toxicol, 2004, 18: $232-233$

24 Harada K, Xu F, Ono K, et al. Effects of PFOS and PFOA on L-type 
$\mathrm{Ca}^{2+}$ currents in guinea-pig ventricular myocytes. Biochem Biophys Res Commun, 2005, 329: 487-494

25 Lau C, Thibodeaux J R, Hanson R G, et al. Effects of perfluorooctanoic acid exposure during pregnancy in the mouse. Toxicol Sci, 2006, 90: 510-518

26 Guruge K S, Yeung L W, Yamanaka N, et al. Gene expression profiles in rat liver treated with pedluoronctanoie acid (PFOA). Toxicol Sci, 2006, 89: 93-107

27 Staskal D F, Diliberto J J, DeVito M J, et al. Toxicokinetics of BDE 47 in female mice: effect of dose, route of exposure, and time. Toxicol Sci, 2005, 83: 215-223

28 Jones-Otazo H A, Clarke J P, Diamond M L, et al. Is house dust the missing exposure pathway for PBDEs? An analysis of the urban fate and human exposure to PBDEs. Environ Sci Technol, 2005, 39: $5121-5130$

29 Meironyté D, Norén K, Bergman A. Analysis of polybrominated diphenyl ethers in Swedish human milk A time-related trend study, 1972 - 1997. J Toxicol Environ Health, 1999, 58: 329-341

30 Schröter-Kermani C, Helm D, Herrmann T, et al. The German environmental specimen bank-application in trend monitoring of polybrominated diphenyl ethers in human blood. Organohalogen Compd, 2000, 47: 49-52

31 Sjödin A, Patterson D G Jr, Bergman Å. Concentrations and spatial variations of polybrominated diphenyl ethers and other organohalogen compounds in Great Lakes air. Environ Sci Technol, 2001, 35: $3830-3833$

32 Nagayama J, Tsuji H, Takasuga T. Comparison between brominated flame retardants and dioxins or organochlorine compounds in blood levels of Japanese adults. Organohalogen Compd, 2000, 48: 27-30

33 Meironyté Guvenius D, Aronsson A, Ekman-Ordeberg G, et al. Human prenatal and postnatal exposure to polybrominated diphenyl ethers, polychlorinated biphenyls, polychlorobiphenylols and pentachlorophenol. Environ Health Perspect, 2003, 111: 1235-1241

34 Hirai T, Furutani H, Myouren M, et al. Concentration of polybrominated diphenyl ethers (PBDEs) in the human bile in relation to those in the liver and blood. Organohalogen Compd, 2002, 58: 277-280

35 van Bavel B, Hardell L, Kitti A, et al. High levels of PBDE in 5\% of 220 blood samples from the Swedish population. Organohalogen Compd, 2002, 58: 161-164

36 Mazdai A, Dodder N G, Abernathy M P, et al. Polybrominated diphenyl ethers in maternal and fetal blood samples. Environ Health Perspect, 2003, 111: 1249-1252

37 Harrad S, Porter L. Concentrations of polybrominated diphenyl ethers in blood serum from New Zealand. Chemosphere, 2007, 66: 2019-2023

38 Takasuga T, Senthilkumar K, Takemori H, et al. Impact of fermented brown rice with Aspergillus oryzae (FEBRA) intake and concentrations of polybrominated diphenylethers (PBDEs) in blood of humans from Japan. Chemosphere, 2004, 57: 795-811

39 Carrizo D, Grimalt J O. Influence of breastfeeding in the accumulation of polybromodiphenyl ethers during the first years of child growth. Environ Sci Technol, 2007, 41: 4907-4912

40 Thomas G O, Wilkinson M, Hodson S, et al. Organohalogen chemicals in human blood from United Kingdom. Environ Pollut, 2006, 141: $30-41$
41 Sjödin A, Jones R, Focant J F, et al. Retrospective time-trend study of polybrominated diphenyl ether and polybrominated and polychlorinated biphenyl levels in human serum from the United States. Environ Health Perspect, 2004, 112: 654-658

42 Bradman A, Fenster L, Sjödin A, et al. Polybrominated diphenyl ether levels in the blood of pregnant women living in an agricultura community in California. Environ Health Perspect, 2007, 115: 71-74

43 Lee S J, Ikonomou M G, Park H, et al. Polybrominated diphenyl ethers in blood from Korean incinerator workers and general population. Chemosphere, 2007, 67: 489-497

44 Bi X H, Qu W Y, Sheng G Y, et al. Polybrominated diphenyl ethers in South China maternal and fetal blood and breast milk. Environ Pollut 2006, 144: 1024-1030

45 Hites R A. Polybrominated diphenyl ethers in the environment and in people: A meta-analysis of concentrations. Environ Sci Technol, 2004, 38: $945-956$

46 Taves D R. Evidence that there are two forms of fluoride in human serum. Nature, 1968, 217: 1050-1051

47 Hansen K J, Clemen L A, Ellefson, et al. Compound-specific, quantitative characterization of organic fluorochemicals in biological matrices. Environ Sci Technol, 2001, 35: 766-770

48 Kannan K, Corsolini S, Falandysz J, et al. Perfluorooctanesulfonate and related fluorochemicals in human blood from several countries. Environ Sci Technol, 2004, 38: 4489-4495

49 Guruge K S, Taniyasu S, Yamashita N, et al. Perfluorinated organic compounds in human blood serum and seminal plasma: a study of urban and rural tea worker populations in Sri Lanka. J Environ Monit, 2005, 7: $371-377$

50 Taniyasu S, Kannan K, Horii Y, et al. A Survey of perfluorooctane sulfonate and related perfluorinated organic compounds in water, fish, birds, and humans from Japan. Environ Sci Technol, 2003, 37: $2634-2639$

51 Inoue K, Okada F, Ito R, et al. Perfluorooctane sulfonate (PFOS) and related perfluorinated compounds in human maternal and cord blood samples: Assessment of PFOS exposure in a susceptible population during pregnancy. Environ Health Perspect, 2004, 112: 1204-1207

52 Ehresman D J, Froehlich J W, Olsen G W, et al. Comparison of human whole blood, plasma, and serum matrices for the determination of perfluorooctanesulfonate (PFOS), perfluorooctanoate (PFOA), and other fluorochemicals. Environ Res, 2007, 103: 176-184

53 Apelberg B J, Goldman L R, Calafat A M, et al. Determinants of fetal exposure to polyfluoroalkyl compounds in Baltimore, Maryland. Environ Sci Technol, 2007, 41: 3891-3897

54 Calafat A M, Kuklenyik Z, Caudill S P, et al. Perfluorochemicals in pooled serum samples from United States residents in 2001 and 2002. Environ Sci Technol, 2006, 40: 2128-2134

55 Falandysz J, Taniyasu S, Gulkowska A, et al. Is fish a major source of fluorinated surfactants and repellents in humans living on the Baltic coast? Environ Sci Technol, 2006, 40: 748-751

56 Ericson I, Gómez M, Nadal M, et al. Perfluorinated chemicals in blood of residents in Catalonia (Spain) in relation to age and gender: A pilot study. Environ Int, 2007, 33: 616-623

57 Kärrman A, van Bavel B, Järnberg U, et al. Perfluorinated chemicals in relation to other persistent organic pollutants in human blood Chemosphere, 2006, 64: 1582-1591 
58 Yeung L W Y, So M K, Jiang G, et al. Perfluorooctanesulfonate and related fluorochemicals in human blood samples from China. Environ Sci Technol, 2006, 40: 715-720

59 Olsen G W, Huang H Y, Helzlsouer K J, et al. Historical comparison of perfluorooctanesulfonate, perfluorooctanoate, and other fluorochemicals in human blood. Environ Health Perspect, 2005, 113: $539-545$

60 Calafat A M, Needham L L, Kuklenyik Z, et al. Perfluorinated chemicals in selected residents of the American continent. Chemosphere, 2006, 63: 490-496

61 Olsen G W, Church T R, Miller J P, et al. Perfluorooctanesulfonate and other fluorochemicals in the serum of American Red Cross adult blood donors-Research. Environ Health Perspect, 2003, 111: $1892-1901$

62 Kuklenyik Z, Reich J A, Tully J S, et al. Automated solid-phase extraction and measurement of perfluorinated organic acids and amides in human serum and milk. Environ Sci Technol, 2004, 38: $3698-3704$

63 Olsen G W, Church T R, Larson E B, et al. Serum concentrations of perfluorooctanesulfonate and other fluorochemicals in an elderly population from Seattle, Washington. Chemosphere, 2004, 54: $1599-1611$

64 Calafat A M, Kuklenyik Z, Reidy J A, et al. Serum Concentrations of 11 Polyfluoroalkyl compounds in the US population: Data from the national health and nutrition examination survey (NHANES) 1999-2000. Environ Sci Technol, 2007, 41, 2237-2242

65 Kärrman A, Langlois I, van Bavel B, et al. Identification and pattern of perfluorooctane sulfonate (PFOS) isomers in human serum and plasma. Environ Int, 2007, 33: 782-788

66 Harada K, Inoue K, Morikawa A, et al. Renal clearance of perfluorooctane sulfonate and perfluorooctanoate in humans and their species-specific excretion. Environ Res, 2005, 99: 253-261

67 Darnerud P O, Eriksen G S, Johannesson T, et al. Polybrominated diphenyl ethers: Occurrence, dietary exposure, and toxicology. Environ Health Perspect, 2001, 109: 49-68

68 Betts K S. What fate for brominated fire retardants. Environ Sci Technol, 2000, 34: 223A-226A

69 Wang Y W, Jiang G B, Lam P K S, et al. Polybrominated diphenyl ether in the east Asian environment: A critical review. Environ Int, 2007, 33: $963-973$

70 Hori S, Akutsu K, Oda H, et al. Development of an analysis method for polybrominated diphenyl ethers and their levels in Japanese human Mother's milk. Organohalogen Compd, 2002, 58: 245-248

71 Kazda R, Hajšlová J, Poustka J, et al. Determination of polybrominated diphenyl ethers in human milk samples in the Zzech Republic comparative study of negative chemical ionization mass spectrometry and time-of-flight high resolution mass spectrometry. Anal Chim Acta, 2004, 520: 237-243

72 Kalaztzi O I, Martin F L, Thomas G O, et al. Different levels of polybrominated diphenyl ethers (PBDEs) and chlorinated compounds in breast milk from two UK regions. Environ Health Perspect, 2004, 112: $1085-1091$

73 A preliminary study on PBDEs and HBCD in blood and milk from Mexican women. The third International workshop on brimniated flame retardants, 2004, Canada, 483-488
74 Fängström B, Strid A, Grandjean P, et al. A retrospective study of PBDEs and PCBs in human milk from the Faroe Islands. Environ Health, 2005, 14: 4-12

75 Vieth B, Herrmann T, Mielke H, et al. PBDE levels in human milk: The situation in Germany and potential influencing factors-a controlled study. Organohalogen Compd, 2004, 66: 2643-2648

76 Tsydenova O, Sudaryanto A, Kajiwara N, et al. Organohalogen compounds in human breast milk from Republic of Buryatia, Russia. Environ Pollut, 2007, 146: 225 - 232

77 Ingelido A M, Ballard T, Dellatte E, et al. Polychlorinated biphenyls (PCBs) and polybrominated diphenyl ethers (PBDEs) in milk from Italian women living in Rome and Venice. Chemosphere, 2007, 67 $\mathrm{S} 301-\mathrm{S} 306$

78 Ryan J J, Patry B. Determination of brominated diphenyl ethers (BDEs) and levels in Canadian human milks. Organohalogen Compd, 2000, 47: $57-60$

79 Akutsu K, Kitagawa M, Nakazawa H, et al. Time-trend (1973-2000) of polybrominated diphenyl ethers in Japanese mother's milk. Chemosphere, 2003, 53: 645-654

80 Gill U, Chu I, Ryan J J, et al. Polybrominated diphenyl ethers: Human tissue levels and toxicology. Rev Environ Contam T, 2004, 183 $55-97$

81 Ryan J J, Patry B. Body burdens and exposure from food for polybrominated diphenyl ethers (BDEs) in Canada. Organohalogen Compd, 2001, 51: 226-229

82 Sjödin A, McGahee E E, Focant J F, et al. Semiautomated high-throughput extraction and cleanup method for the measurement of polybrominated diphenyl ethers and polybrominated and polychlorinated biphenyls in breast milk. Anal Chem, 2004, 76: $4508-4514$

83 Strandman T, Koistinen J, Vartiainen T. Polybrominated diphenyl ethers (PBDEs) in placenta and human milk. Organohalogen Compd, 2000, 47: 61-64

84 She J W, Holden A, Sharp M, et al. Polybrominated diphenyl ethers (PBDEs) and polychlorinated biphenyl (PCBs) in breast milk from the Pacific Northwest. Chemosphere, 2007, 67: S307-S317

85 Darnerud P O, Atuma S, Aune M, et al. Polybrominated diphenyl ethers (PBDEs) in breast milk from primiparous women in Uppsala county, Sweden. Organohalogen Compd, 1998, 35: 411-414

86 Atuma S, Aune M, Darnerud P O, et al. Polybrominated diphenyl ethers PBDEs in human milk from Sweden. Am Chem Soc Symp Ser 2001, 773: 235-242

87 Jaraczewska K, Lulek J, Covaci A M, et al. Distribution of polychlorinated biphenyls, organochlorine pesticides and polybrominated diphenyl ethers in human umbilical cord serum, maternal serum and milk from Wielkopolska region, Poland. Sci Total Environ, 2006, 372 $21-31$

88 Toms L-M, Harden F A, Symons R K, et al. Polybrominated diphenyl ethers (PBDEs) in human milk from Australia. Chemosphere, 2007, 68: $797-803$

89 Ohta S, Ishizuka D, Nishimura H, et al. Real situation of contamination by polybrominated diphenyl ethers as flame retardants in market fish and mother milk of Japan. Organohalogen Compd, 2000, 47: $218-221$

90 Sudaryanto A, Kajiwara N, Tsydenova O, et al. Global contamination of 
PBDEs in human milk from Asia. Organohalogen Compd, 2005, 67: $1315-1318$

91 Päpke O, Bathe L, Bergman $\AA$, et al. Determination of PBDEs in human milk from the United States Comparison of results from tree laboratories. Organohalogen Compd, 2001, 52: 197-200

92 Eslami B, Koizumi A, Ohta S, et al. Large-scale evaluation of the current level of polybrominated diphenyl ethers (PBDEs) in breast milk from 13 regions of Japan. Chemosphere, 2006, 63: 554-561

93 Ryan J J, Patry B, Mills P, et al. Recent trends in levels of brominated diphenyl ethers (BDEs). Organohalogen Compd, 2002, 58: 173-176

94 Erdoğrul O, Covaci A, Kurtul N, et al. Levels of organohalogenated persistent pollutants in human milk from Kahramanmaras region, Turkey. Environ Int, 2004, 30: 659-666

95 Schecter A, Pavuk M, Päpke O, et al. Polybrominated diphenyl ethers (PBDEs) in US mother's milk. Environ Health Perspect, 2003, 111: $1723-1729$

96 So M K, Yamashita N, Taniyasu S, et al. Health risks in infants associated with exposure to perfluorinated compounds in human breast milk from Zhoushan, China. Environ Sci Technol, 2006, 40: 2924-2929

97 Kärrman A, Ericson I, van Bavel B, et al. Exposure of perfluorinated chemicals through lactation: levels of matched human milk and serum and a temporal trend, 1996-2004, in Sweden. Environ Health Perspect, 2007, 115: 226-230

98 Choi J, Fujimaki S, Kitamura K, et al. Polybrominated dibenzo-p-dioxins, dibenzofurans, and diphenyl ethers in Japanese human adipose tissue. Environ Sci Technol, 2003, 37: 817-821

99 Kunisue T, Takayanagi N, Isobe T, et al. Polybrominated diphenyl ethers and persistent organochlorines in Japanese human adipose tissues. Environ Int, 2007, 33: 1048-1056

100 Li Q Q, Loganath A, Chong Y S, et al. Determination and occurrence of polybrominated diphenyl ethers in maternal adipose tissue from inhabitants of Singapore. J Chromatogr B, 2005, 819: 253-257

101 Covaci A, de Boer J, Ryan J J, et al. Distribution of organobrominated and organchlorinated contaminants in Belgian human adipose tissue. Environ Res A, 2002, 88: 210-218

102 Meironyté Guvenius D, Bergman Å, Norén K. Polybrominated diphenyl ethers in Swedish human liver and adipose tissue. Arch Environ Contam Toxicol, 2001, 40: 564-570

103 Haglund P S, Zook D R, Buser H R, et al. Identification and quanti- fication of polybrominated diphenyl ethers and methoxy-polybrominated diphenyl ethers in Baltic biota. Environ Sci Technol, 1997, 31: 3281-3287

104 Strandman T, Koistinen J, Kiviranta H, et al. Levels of some polybrominated diphenyl ethers (PBDEs) in fish and human adipose tissue in Finland. Organohalogen Compd, 1999, 40: 355-358

105 Smeds A, Saukko P. Brominated flame retardants and phenolic endocrine disrupters in Finnish human adipose tissue. Chemosphere, 2003, 53: $1123-1130$

106 Meneses M, Wingfors H, Schuhmacher M, et al. Polybrominated diphenyl ethers detected in human adipose tissue from Spain. Chemosphere, 1999, 39: 2271-2278

107 Fernandez M F, Araque P, Kiviranta H, et al. PBDEs and PBBs in the adipose tissue of women from Spain. Chemosphere, 2007, 66: $377-383$

108 Crhova S, Cerna M, Grabic R, et al. Polybrominated flame retardants in human adipose tissue in Czech Republic inhabitants: The pilot study. Organohalogen Compd, 2002, 58: 241-244

109 She J, Petreas M, Winkler J, et al. PBDEs in the San Francisco Bay area: measurements in harbor seal and human breast adipose tissue. Chemosphere, 2002, 46: 697-707

110 Johnson-Restrepo B, Kannan K, Rapaport D P, et al. Polybrominated diphenyl ethers and polychlorinated biphenyls in human adipose tissue from New York. Environ Sci Technol, 2005, 39: 5177-5182

111 Qu W Y, Bi X H, Sheng G Y, et al. Exposure to polybrominated diphenyl ethers among workers at an electronic waste dismantling region in Guangdong, China. Environ Int, 2007, 33: 1029-1034

112 Thuresson K, Bergman A, Jakobsson K. Occupational exposure to commercial decabromodiphenyl ether in workers manufacturing or handling flame-retarded rubber. Environ Sci Technol, 2005, 39: 1980-1986

113 Thuresson K, Bergman A, Rothenbacher K, et al. Polybrominated diphenyl ether exposure to electronics recycling workers-a follow up study. Chemosphere, 2006, 64: 1855-1861

114 Schecter A, Harris T R, Päpke O, et al. Polybrominated diphenyl ether (PBDE) levels in the blood of pure vegetarians (vegans). Toxicol Environ Chem, 2006, 88: 107-112

115 Meng X Z, Zeng E Y, Yu LP, et al. Assessment of human exposure to polybrominated diphenyl ethers in China via fish consumption and inhalation. Environ Sci Technol, 2007, 41: 4882-4887 